\title{
Do natural ao construído: proposta para estimar acúmulo de calor em metrópoles
}

\author{
From natural to constructed: a proposal \\ to estimate heat accumulation in metropolises
}

Ruskin Freitas [I] Jaucele Azerêdo [II]

\begin{abstract}
Resumo
A transformação de um ambiente natural em um ambiente construído ocasiona a formação de diferentes climas urbanos, de acordo com geometria urbana, materiais e atividades. 0 objetivo deste artigo é apresentar uma metodologia para se estimar o acúmulo de calor em recintos urbanos, considerando a influência de dez fatores climáticos, avaliados através de uma escala graduada em cinco níveis: acúmulo de calor negativo, nulo, baixo, médio e alto, podendo chegar a um total de seis graus positivos $\left(+6,0^{\circ} \mathrm{C}\right)$, em relação àquele valor verificado na estação meteorológica de referência. A aplicação dessa metodologia, desenvolvida a partir de pesquisas diversas, poderá embasar comparações entre metrópoles e orientar intervenções que visem à satisfação do usuário, à eficiência dos espaços e à sustentabilidade ambiental.
\end{abstract}

Palavras-chave: urbanização; climas urbanos; acúmulo de calor; Recife.

\begin{abstract}
The transformation from a natural environment to a built environment causes the formation of different urban climates, according to urban geometry, materials and activities. The objective of this article is to present a methodology to estimate heat accumulation in urban precincts, according to the influence of ten climatic factors, assessed through values on a scale graduated into five levels: accumulation of negative, null, low, medium and high heat, the latter being able to reach six positive degrees $\left(+6.0^{\circ} \mathrm{C}\right)$ in relation to the value verified in the reference meteorological station. The application of this methodology can support comparisons between metropolises and guide interventions aimed at user satisfaction, the efficiency of the built space and environmental sustainability.
\end{abstract}

Keywords: urbanization; spatial transformations; urban climates; heat accumulation; Recife. 


\section{Introdução}

O processo de urbanização caracteriza-se pela substituição de elementos naturais, tais como, solo permeável, cursos de água e vegetação, por elementos construídos, a exemplo de superfícies impermeáveis, sistema viário e volumes edificados. Essas transformações têm sido objeto de abordagens diversas. A mais usual é observar o aumento populacional e a pressão que a densidade demográfica exerce sobre a natureza e a sociedade. De acordo com dados divulgados pelo relatório World Population Prospects - The 2017 Revision (United Nations, 2017, p. 1), a população mundial totalizava, em meados de 2017, em torno de 7,6 bilhões de habitantes. Destes, 55\% encontravam-se em áreas urbanas; e há uma estimativa de que, em meados deste século, esse percentual alcance $68 \%$, o que corresponde a um crescimento de 2,5 bilhões de habitantes entre 2018 e 2050 (United Nations, 2019, p. 1). Assim sendo, pode-se afirmar que o futuro da população mundial é ser urbana.

Pires, Kneib e Ribeiro (2020, p. 248) afirmam que "a forma como esses novos habitantes serão acomodados no território tem impactos ambientais, sociais e econômicos". Alvin, Kato e Rossin (2015, p. 84), mais especificamente, lembram que "o crescimento desordenado das cidades gera inúmeros problemas com sérias consequências para a sociedade, tais como impermeabilização do solo, alterações na drenagem urbana, [...] alteração de clima, entre outros".

A transformação do ambiente natural em um ambiente construído ocasiona um aumento da temperatura, consequentemente, um acúmulo de calor, cuja intensidade depende de elementos, formas, atividades, entre outros diversos fatores associados à formação de climas urbanos, ou seja, a intensidade de possíveis transformações socioespaciais influenciará mudanças no comportamento de elementos climáticos, diferentemente, em cada local, em geral, aumentando a temperatura do ar, diminuindo a umidade relativa do ar, modificando a direção e a velocidade dos ventos. É importante enfatizar que a intensidade das alterações dos valores climáticos é diretamente proporcional às transformações ocasionadas nos processos de mudanças do ambiente.

A simples comparação natural-construído ou rural-urbano não dá conta de todas essas transformações. Como afirmam Oke et al. (2017, p. 168), o "processo completo envolve a consideração de três conjuntos de fatores entrelaçados: propriedades térmicas, disponibilidade de umidade e forma geométrica". Ou seja, os fenômenos de absorção, estocagem e emissão de calor dependem de fatores climáticos naturais e antrópicos, nos quais a combinação de materiais, elementos e formas pode originar uma enorme diversidade de situações. Além disso, há que se considerar o uso prioritário a que se destina o recinto urbano, pois o uso (residencial, comercial, industrial) pode se configurar como atrativo à realização de atividades e de públicos específicos. Nesse sentido, cada contexto deve ser considerado a partir de suas particularidades.

Stewart e Oke (2012, p. 1885), após realizarem uma extensa revisão de diversos estudos sobre climas urbanos, apresentaram uma nova classificação de 17 regiões homogêneas chamadas "zonas climáticas urbanas", que variam de áreas semirrurais a áreas intensamente urbanizadas: "Definimos formalmente as zonas climáticas locais como regiões de 
cobertura uniforme de superfície, estrutura, material e atividade humana que se estendem por centenas de metros a vários quilômetros em escala horizontal".

No entanto, na prática, dificilmente são encontradas regiões homogêneas em meio urbano, sobretudo nas metrópoles brasileiras, marcadas por diversidade ambiental, fragmentação socioeconômica, multiplicidade de parâmetros urbanísticos e zonas institucionais, gerando diferentes tipos morfológicos justapostos, em geral, de pequenas dimensões. As diferentes conformações urbanas geram, por sua vez, diferentes níveis de acúmulo de calor.

O estudo de Stewart e Oke (ibid.) é muito importante para caracterizações, classificações e comparações entre locais, como também, tem destacada relevância na associação entre características morfológicas e medição de elementos climáticos locais, podendo apontar influências recíprocas entre esses elementos. No entanto, são importantes contextualização, desdobramentos e aprofundamentos, em escala local. Almeida (2019, p. 61) aponta que "o sistema LCZ é genérico e pode não capturar as peculiaridades de cada sítio urbano e rural. Sua visão da paisagem é altamente reducionista, e, como todas as classificações, seus poderes descritivos e explicativos são limitados". LCZ é a sigla para Zonas Climáticas Urbanas, em língua inglesa.

Estudos sobre climas se iniciam com a observação dos elementos climáticos, avaliando-se dados quanto a temperatura do ar, umidade relativa do ar, precipitação, direção e velocidade dos ventos, que caracterizam o tempo atmosférico. Valores referentes a esses elementos climáticos são coletados em estações meteorológicas de referência, atualizados praticamente em tempo real e publicados, diariamente, pelo Instituto Nacional de Meteorologia - Inmet e pelo Instituto Nacional de Pesquisas Espaciais - Inpe. Esses dados, em geral, são coletados em locais cujas condições se aproximam das características naturais, com mínima influência das intervenções humanas (ambiente com solo natural, permeável ao sol e ao vento).

O tempo atmosférico, quando observado por um longo período de tempo cronológico, embasa os estudos relativos ao clima, por meio de séries históricas, que consideram, geralmente, 30 anos de observação de dados. Como afirma Ayoade (1991, p. 2), "o clima apresenta uma generalização, enquanto o tempo lida com eventos específicos". Porém, o clima não pode ser tido apenas como uma média do comportamento de elementos climáticos, mas também devem ser incluídas as suas variações, em uma concepção dinâmica, tão bem-descrita na obra de Monteiro (1976).

O clima urbano, por sua vez, "é um sistema que abrange o clima de um dado espaço terrestre e sua urbanização" (Monteiro e Mendonça, 2003, p. 19). A depender da qualificação profissional e dos objetivos de investigação, os climas urbanos podem abranger áreas de diferentes dimensões e com inúmeras variáveis. Aqui, a referência tomada é o comportamento diverso do conjunto de elementos climáticos em um recorte espacial, identificado pelo seu caráter urbano, podendo ser uno ou múltiplo, dependendo dos fatores climáticos naturais e antrópicos.

A formação de climas urbanos é um tema de fundamental importância para os estudos sobre conforto ambiental, em arquitetura e urbanismo. Mesmo que se considere apenas o conforto térmico, o seu principal elemento referencial - a temperatura - é influenciado 
por fatores climáticos naturais e antrópicos e, ainda, pela variação de outros elementos climáticos, a exemplo de pluviosidade, umidade relativa do ar e exposição aos ventos, em direção e velocidade.

Entre os fatores climáticos antrópicos, destacam-se os volumes edificados, a superfície do solo, o traçado urbano e as atividades antrópicas. Esses fatores modificam as características regionais do clima, em diferentes escalas, formando de mesoclimas a microclimas urbanos - variações locais, no comportamento dos elementos climáticos. Um dos principais resultados dessa modificação local é a constituição do acúmulo de calor.

Diversos autores já se debruçaram sobre esse tema, realizando pesquisas bibliográficas e documentais, além de pesquisas de campo, com observações diretas, medições das variáveis climático-ambientais em diversos períodos do ano e análises aprofundadas, que comprovam o aumento de temperatura em ambientes urbanos. Dentre esses autores, podem ser citados Monteiro (1976), Landsberg (1981), Lombardo (1985), Mascaró (1996), Tarifa e Azevedo (2001), Freitas (2008) e Azerêdo (2017).

A capital do estado de Pernambuco é aqui tomada como objeto empírico. Pela sua localização, entre os trópicos de Câncer e de Capricórnio, em baixa latitude, a $8^{\circ} 23^{\prime}$ ao sul da linha do Equador, essa cidade se insere na zona térmica quente da Terra, ou seja, em clima tropical. 0 fato de estar na costa oriental brasileira, exposta aos ventos alísios predominantemente de sudeste, às margens do oceano Atlântico, atribui-Ihe o caráter de clima litorâneo. Assim, mais especificamente, a denominação climática para a região onde Recife se insere é clima tropical litorâneo quente e úmido, cujas principais características são as altas temperaturas durante todo o ano e a elevada umidade relativa do ar, em torno de $80 \%$, o que contribui para uma baixa amplitude térmica, ao reduzir as temperaturas extremas. Diminuem-se as máximas e elevam-se as mínimas, conformando uma temperatura média anual de aproximadamente $26^{\circ} \mathrm{C}$, considerada uma temperatura mediana, sobretudo, quando estamos expostos a ventos constantes e moderados, em torno de $3 \mathrm{~m} / \mathrm{s}$, de acordo com as Normais Climatológicas, período 19812010, disponibilizadas pelo Instituto Nacional de Meteorologia/Inmet.

Supondo-se que, em um determinado momento, o tempo atmosférico encontre-se em condições médias, em área não urbanizada, próxima ao natural, no bairro do Curado, por exemplo, a estação meteorológica, situada naquele bairro, poderia estar registrando uma temperatura de $25,5{ }^{\circ} \mathrm{C}$. Esse valor corresponde às características médias regionais do clima tropical litorâneo quente e úmido de Recife, segundo o Inmet. Em outros locais da cidade, essa temperatura do ar não será a mesma. Em geral, será um pouco maior. Pesquisas diversas, desenvolvidas pelo Laboratório de Conforto Ambiental - Lacam, da Universidade Federal de Pernambuco - UFPE, especificamente identificando a diversidade microclimática em recintos distintos, a partir da realização de medições de variáveis climáticas, demonstraram a possibilidade de que o acúmulo de calor pode alcançar até $6^{\circ} \mathrm{C}$, em Recife.

No caso de uma análise ou de estudos visando a intervenções em determinados recintos da cidade, em diferentes estágios de urbanização, o uso exclusivo de dados coletados em locais com características naturais, a exemplo das estações meteorológicas, não dá a 
ideia exata do comportamento dos elementos climáticos em local intensamente urbanizado, obviamente, em virtude das diferenças existentes de uso, ocupação, geometria urbana e materiais entre as áreas.

Considerando a inexistência de uma rede de estações que possa ser utilizada para aferir temperatura do ar e a dificuldade em se realizarem periódicas e sistemáticas baterias de medições, em cada bairro ou recinto urbano da cidade, poderia ser desenvolvida uma metodologia que proporcionasse uma estimativa de valores de temperatura de cada determinada área, para fins não científicos. Dessa maneira, a partir da identificação de áreas-tipo, distribuídas pela cidade, e considerando elementos climáticos e elementos da morfologia urbana, poderia ser estimada uma temperatura máxima para cada localidade, relacionando o nível de urbanização ao acúmulo de calor.

O objetivo deste artigo é apresentar uma metodologia, desenvolvida com vistas a estimar a temperatura do ar máxima a ser alcançada em um dado recinto urbano (praça, largo, cruzamento entre vias, um trecho de uma rua ou de uma avenida), a partir da avaliação de dez fatores climáticos.

Tomando-se como referência a temperatura do ar registrada na estação meteorológica, pode-se presumir que, em um ambiente com as mesmas características naturais e morfológicas, tenha-se temperatura semelhante. No entanto, outro ambiente, que esteja exposto a diferentes fatores climáticos locais e que apresente características morfológicas diversas, apresentará outro valor de temperatura do ar, devido ao acúmulo de calor.

Para uma maior compreensão, foram abordados alguns breves conceitos:
1) Temperatura - é um dos conceitos centrais da termodinâmica e uma das sete grandezas fundamentais do Sistema Internacional (SI), sendo mensurável através de um termômetro. "Todo corpo possui uma propriedade chamada de temperatura. Quando dois corpos estão em equilíbrio térmico, suas temperaturas são iguais" (Halliday; Resnick e Walker, 2012, pp. 184-185).

2) Temperatura do ar - "é a medida do calor sensível nele armazenado, sendo comumente dada em graus Celsius ou Fahrenheit e medida por termômetros" (Mendonça e Danni-Oliveira, 2009, p. 49). Considerada um elemento climático, ela é muito utilizada para caracterizar um determinado local, utilizando-se o seu valor instantâneo ou médias diárias, mensais e anuais. A temperatura do ar varia, no tempo e no espaço, em função de fatores climáticos, naturais e antrópicos, locais e globais.

3) Calor - a "variação de temperatura se deve a uma mudança da energia térmica do sistema por causa da troca de energia entre o sistema e o ambiente. [...] A energia transferida é chamada de calor". Em outras palavras, calor "é a energia trocada entre um sistema e o ambiente devido a uma diferença de temperatura". Ou seja, quanto maior a diferença de temperatura, maior a quantidade de energia trocada entre os meios em questão, até que se estabeleça o equilíbrio térmico. Como o calor é uma energia transferida, a sua unidade de medida no Sistema Internacional é o Joule (J), de acordo com Halliday, Resnick e Walker (2012, pp. 191-193).

4) Acúmulo de calor - especificamente, em se tratando de acúmulo de calor, tem-se que atentar para o valor que será considerado como referência, que é o valor de temperatura 
do ar disponibilizado pelas estações meteorológicas de referência do Inmet (Automática e Convencional). Ao se avaliar o ambiente através dos dez fatores climáticos e se estimar a quantidade em graus Celsius $\left({ }^{\circ} \mathrm{C}\right)$ do acúmulo de calor, soma-se esse valor ao valor máximo da temperatura do ar disponibilizado pela estação de referência, alcançando-se a temperatura estimada do ambiente em estudo. 0 acúmulo de calor em meio urbano, portanto, nada mais é do que a diferença de temperatura em graus Celsius $\left({ }^{\circ} \mathrm{C}\right)$, entre dois ambientes em questão, sendo um deles a estação meteorológica, no caso deste artigo.

Propõe-se, então, a construção de uma escala graduada em cinco níveis: acúmulo de calor negativo, nulo, baixo, médio e alto acúmulo de calor, conforme apresentado no Quadro 1. Os valores foram atribuídos, de maneira estimativa, a partir do potencial acúmulo de calor, em função da influência de cada fator.

É aqui estimado um raio de influência de 25 metros, a partir do ponto considerado de referência para a caracterização dos elementos climáticos em uma estação meteorológica ou em um recinto urbano. Esse raio, no entanto, pode ser variável, para mais ou para menos, a depender das condições do entorno imediato, seja pela presença de elementos naturais (massas de água, massas de vegetação, variações topográficas), seja por transformações da forma urbana e de elementos construídos (geometria urbana, volumes edificados, sistema viários, atividades antrópicas).

Quadro 1 - Influência de cada fator climático sobre o acúmulo de calor em recintos urbanos

\begin{tabular}{|l|c|}
\hline \multicolumn{1}{|c|}{$\begin{array}{c}\text { Níveis de influência de fatores climáticos sobre o comportamento } \\
\text { da temperatura do ar, repercutindo sobre o acúmulo de calor, } \\
\text { em recintos urbanos }\end{array}$} & $\begin{array}{c}\text { Acúmulo de calor ( }{ }^{\circ} \mathrm{C} \text { ) } \\
\text { estimado, em função de } \\
\text { cada fator climático local }\end{array}$ \\
\hline $\begin{array}{l}\text { No primeiro nível, determinado fator influencia a diminuição da temperatura do ar, } \\
\text { caracterizando-se o recinto, com condições muito mais próximas de um ambiente } \\
\text { natural, do que aquelas verificadas na estação meteorológica. }\end{array}$ & $-0,25$ \\
\hline $\begin{array}{l}\text { No segundo nível, determinado fator não interfere na temperatura do ar, caracterizan- } \\
\text { do-se o recinto por sofrer intervenção antrópica com baixa intensidade, apresentando } \\
\text { características próximas de um ambiente natural. }\end{array}$ & +0 \\
\hline $\begin{array}{l}\text { No terceiro nível, determinado fator influencia o aumento da temperatura do ar, } \\
\text { que tem um pequeno acréscimo, caracterizando-se o recinto por sofrer intervenção } \\
\text { antrópica, distanciando-se das características naturais. }\end{array}$ & $+0,25$ \\
\hline $\begin{array}{l}\text { No quarto nível, determinado fator influencia o aumento da temperatura do ar, } \\
\text { que tem um acréscimo, decorrente de significativa variação no comportamento dos } \\
\text { elementos climáticos e/ou na configuração dos elementos morfológicos. }\end{array}$ & $+0,50$ \\
\hline $\begin{array}{l}\text { No quinto nível, determinado fator influencia o aumento da temperatura do ar, que } \\
\text { tem um acréscimo alto, em decorrência de intensa intervenção antrópica, com total } \\
\text { perda de elementos naturais. }\end{array}$ & $+0,75$ \\
\hline
\end{tabular}

Fonte: elaboração Ruskin Freitas. 
Para a análise de um determinado recinto urbano, devem ser considerados diversos fatores climáticos, que contribuem, um a um, com estimado acúmulo de calor, a depender da intensidade de transformações socioespaciais e ambientais e da maneira como influenciam os elementos climáticos.

Esses fatores estão aqui sintetizados em dez. São eles: altitude, maritimidade, densidade de vegetação arbórea, permeabilidade aos ventos, permeabilidade do solo, exposição ao sol, densidade construída, usos e sistema viário, materiais de construção e dinâmica da volumetria. Os valores atribuídos ao acúmulo de calor, decorrente de cada um desses fatores (de $-0,5$ a $\left.+0,75^{\circ} \mathrm{C}\right)$, darão um valor total, que pode chegar a seis graus positivos $\left(+6,0{ }^{\circ} \mathrm{C}\right)$, em relação àquele valor verificado na estação meteorológica de referência, como maior temperatura diária.

Para a caracterização e classificação final de um determinado recinto urbano, deverá ser considerada a soma de valores atribuídos ao acúmulo de calor, em decorrência de cada um dos dez fatores observados. 0 valor final poderá ser classificado também em cinco níveis, porém, não em relação a cada fator e sim ao somatório dos valores atribuídos ao conjunto dos dez fatores, podendo resultar em acúmulo de calor negativo, nulo, baixo, médio e alto acúmulo de calor, conforme Quadro 2.

Essa metodologia baseia-se em uma avaliação direta e quantitativa, tipo lista de checagem, para se atribuir um determinado valor. Porém, recomenda-se que ela seja acompanhada por um processo de análise mais detaIhado e qualitativo, considerando as influências recíprocas entre fatores diversos.

Os quadros apresentados tomaram como base o fato de que, em Recife-PE, a partir de pesquisas realizadas desde o ano de 1997, o acúmulo de calor observado, em recintos urbanos, nunca ultrapassou os $6^{\circ} \mathrm{C}$. Citam-se estudos desenvolvidos na cidade e, por vezes, especificamente em alguns bairros, a exemplo de Várzea, Casa Amarela, Encruzilhada, Água Fria, Boa Vista, Espinheiro, entre outros (Freitas, 2008; Barros e Lombardo, 2013; Freitas e Azerêdo, 2014; França et al., 2015; Azerêdo, 2017; Moreira et al., 2017).

Quadro 2 - Níveis de acúmulo de calor, em função de dez fatores climáticos locais

\begin{tabular}{|c|c|}
\hline $\begin{array}{c}\text { Comportamento da temperatura, repercutindo } \\
\text { sobre o acúmulo de calor, em recintos urbanos }\end{array}$ & $\begin{array}{c}\text { Acúmulo de calor }\left({ }^{\circ} \mathrm{C}\right) \text { estimado, em função } \\
\text { da soma de dez fatores climáticos locais }\end{array}$ \\
\hline Acúmulo de calor negativo & $-1,5$ a $-0,25$ \\
\hline Acúmulo de calor nulo & 0 \\
\hline Acúmulo de calor baixo & 0,25 a 1,5 \\
\hline Acúmulo de calor médio & 1,75 a 3,5 \\
\hline Acúmulo de calor alto & 3,75 a 6,0 \\
\hline
\end{tabular}

Fonte: elaboração Ruskin Freitas. 
A seguir, são apresentados os dez fatores climáticos que compõem este estudo.

\section{Altitude}

Altitude é uma distância vertical, medida em metros, entre um determinado ponto na superfície da terra e o nível do mar. Em escala local, muitas vezes, refere-se a esse fator climático natural como sendo topografia, ampliando-se o conceito e a abordagem, para além das alturas, também se referindo à "descrição do local", às variações planialtimétricas e a seus efeitos, sobre elementos climáticos e, inclusive, sobre outros fatores climáticos.

A altitude exerce influência sobre a pressão atmosférica, a exposição à radiação solar e aos ventos, sobre a temperatura, a umidade e a precipitação. Em particular, a altitude exerce influência inversamente proporcional sobre a temperatura. Isso ocorre devido à diminuição da densidade do ar em camadas superiores da atmosfera e também devido ao fato de a superfície terrestre emitir o calor, anteriormente absorvido diretamente ou por reflexão, intensificando-o próximo a essa superfície.

Pode-se dizer que, em média, a cada 100 metros de altitude, a temperatura do ar cai $0,6^{\circ} \mathrm{C}$ (Ayoade, 1991, p. 53), podendo essa queda chegar a $1,0^{\circ} \mathrm{C}$, dependendo também da inclinação, da orientação, do grau de exposição à insolação e à ventilação e do tipo de cobertura da superfície do solo. Assim, os morros apresentam temperaturas um pouco mais baixas que aquelas verificadas na planície. $\mathrm{A}$ apropriação do relevo no desenho ambiental urbano é um fato a ser apreciado, diversificando sua forma e sua influência, entre diferentes locais e, inclusive, entre horários. Por exemplo, durante o dia, as áreas mais baixas, localizadas em fundo de vale, podem ficar sombreadas, enquanto as áreas mais elevadas recebem maior exposição ao sol; porém, à noite, pode haver uma inversão, "os fundos de vales ficam mais quentes e secos que as áreas elevadas, que permanecem mais arejadas em razão da circulação dos ventos" (Schutzer, 2012, p. 84).

Considerando-se que a estação meteorológica de referência, em Recife, está a uma altitude aproximada de apenas 10 metros, todas as áreas localizadas nesse mesmo nível e até 20 metros teriam um acúmulo de calor neutro, ou seja, próximo de $0^{\circ} \mathrm{C}$. Os locais com altitudes entre 20 e 80 metros, em Recife, distribuem-se em um semiarco de morros, localizando-se ao norte, a oeste e a sudoeste. Essas áreas apresentam-se, em sua maioria, densamente ocupadas por assentamentos populares, com baixa densidade de vegetação e de espaços livres. Sobretudo, as áreas de topos de morro e as áreas com declividades voltadas para o leste e sudeste, expostas aos ventos dominantes, apresentariam um pequeno decréscimo de temperatura do ar, em torno de $0,25^{\circ} \mathrm{C}$.

As altitudes acima de 80 metros são raras, concentrando-se no extremo noroeste da cidade, no bairro da Guabiraba, que também se caracteriza pela baixa densidade de ocupação e pela alta densidade de vegetação arbórea. Nesses remotos locais, considerando o fator altitude, ocorreria um decréscimo de temperatura do ar em torno de $0,5^{\circ} \mathrm{C}$.

\section{Maritimidade}

O termo maritimidade é utilizado como um fator climático global, referindo-se à influência de mares e de oceanos sobre os elementos climáticos, em oposição à continentalidade. 
Por analogia, esse termo também é utilizado como fator climático local, referindo-se à influência não apenas de oceanos, mas também de açudes, lagos, rios e todas as grandes massas de água, principalmente, sobre a temperatura do ar e a umidade relativa do ar.

Os materiais possuem propriedades térmicas específicas, por exemplo, quanto à reflexão e à absorção de calor. Uma dessas propriedades é o calor específico. Para Ferraro e Soares (1998, p. 283), o "calor específico pode ser entendido como sendo a medida numérica da quantidade de calor que acarreta uma variação unitária de temperatura na unidade de massa da substância". Ou seja, é a quantidade de calor capaz de fazer um grama de um dado material aumentar sua temperatura em $1^{\circ} \mathrm{C}$.

Como o calor específico da água é mais alto que o da maioria dos solos, será necessário muito mais calor e mais tempo, para haver o aumento da temperatura nas superfícies aquáticas, do que nas superfícies pavimentadas. Da mesma maneira, um maior tempo será decorrido até que ocorra a perda de calor acumulado, gerando significativas diferenças de temperatura entre a terra e a água. Essas diferenças de temperatura dos materiais geram diferenças de temperatura do ar, de pressão atmosférica e a produção de ventos, das zonas de maior pressão, com baixa temperatura do ar, para zonas de menor pressão, com alta temperatura. Observa-se que os locais mais próximos às massas de água apresentam menor temperatura, menor amplitude térmica, maior umidade do ar e maior velocidade do vento. Ribeiro, Braz e Silva (2013, p. 5) calculam que a influência direta da maritimidade sobre a diminuição de temperatura ocorre em uma faixa de terra de até 140 m de distância. Esse valor é variável em função do volume da massa de água e da direção predominante dos ventos. Carvalho (2018, p. 53) considerou as faixas marginais de corpos de água, determinadas pela lei n. 12.651/2012, que trata sobre o Código Florestal Brasileiro.

Considerando-se o conjunto de referências, estima-se que a orla oceânica até uma faixa de $100 \mathrm{~m}$ e as orlas fluviais e lacustres, até uma margem de $30 \mathrm{~m}$, sofreriam influência desse fator maritimidade, diminuindo a temperatura do ar, em torno de $0,5^{\circ} \mathrm{C}$. As áreas a sotavento, em relação às mesmas massas de água, teriam sua área de influência duplicada, porém, com a diminuição da temperatura caindo pela metade, correspondendo a $0,25^{\circ} \mathrm{C}$. Como a estação meteorológica de referência, em Recife, está a uma distância superior a $1 \mathrm{~km}$ do rio Capibaribe e a uma distância superior a 10 km em relação ao oceano Atlântico, pode-se afirmar que esse ponto recebe pouca influência de massas de água. As áreas localizadas nessa mesma condição não sofreriam diminuição de temperatura, relativa a esse fator.

\section{Densidade de vegetação arbórea}

A vegetação é um ser vivo e, como tal, desenvolve um metabolismo e consome energia, retirada do solo e da radiação solar. A utilização dessa energia em processos internos diminui o papel daquela radiação que se transformaria em calor e que seria transmitido para o ambiente. Assim, a vegetação é um dos fatores amenizadores da temperatura do ar, agindo ainda sobre a umidade do ar e sobre a direção e a velocidade dos ventos. 
A evapotranspiração, as superfícies gramadas e o sombreamento proporcionado por espécies arbóreas também constituem maneiras através das quais a ação da vegetação leva à diminuição da temperatura das superfícies e da temperatura do ar.

Freitas (2008, p. 81) destaca o papel da vegetação na formação de microclimas caracterizados pela diminuição de temperatura. Parques, praças, jardins, terrenos vazios, margens de rios e de canais e quintais vegetados, em geral, inseridos em meio a superfícies edificadas, diferenciam-se do seu entorno, apresentando comportamento semelhante a um clima de mata, agindo, no entanto, sobre superfícies de menores dimensões e a sua proximidade direta. A sua configuração espacial dá a ideia de uma ilha de amenidades.

No caso de áreas, eminentemente, urbanas, porém com espaços livres, públicos e privados, compostos por agrupamentos de vegetação arbórea, tais como, praças, vias, quintais e jardins, ocorre a diminuição da temperatura; conforme citaram Mascaró e Mascaró (2002, p. 49), "sob grupos arbóreos a temperatura do ar é de $3^{\circ} \mathrm{C}$ a $4^{\circ} \mathrm{C}$ menor que nas áreas expostas à radiação solar". Azerêdo (2017, p. 429) também confirmou o papel da vegetação na diminuição da temperatura do ar, em seu entorno, ao analisar certas espécies arbóreas, indicando que a influência térmica pode chegar a uma distância de até 90 m, a sotavento do indivíduo arbóreo. Nessa discussão, é imprescindível avaliar a espécie do vegetal, o porte, a densidade foliar, o volume da copa e a velocidade e direção dos ventos predominantes.

Ambientes naturais, com alta densidade de vegetação arbórea, a exemplo de matas e bosques, especialmente, em áreas periféricas, podem contribuir para a diminuição da temperatura, em relação àquela verificada nas estações meteorológicas.

Áreas urbanas com presença de vegetação arbórea, sobretudo constituindo maciços vegetais, compactos ou lineares, com espécies de copa densa, poderiam ter um efeito nulo, em relação ao acúmulo de calor. Ao contrário, à medida que ocorre a substituição de árvores por volumes edificados, ocorre acúmulo de calor. Assim, áreas com presença de vegetação arbórea, com copas densas, porém com indivíduos arbóreos afastados entre si, teriam um acúmulo de calor baixo, ou seja, de 0,25 ${ }^{\circ} \mathrm{C}$. Áreas com presença de vegetação arbórea, porém com indivíduos arbóreos com grandes afastamentos entre si e com espécies de copa rala, poderiam ter um acúmulo de calor médio, ou seja, de $0,5^{\circ} \mathrm{C}$. Áreas desprovidas de arborização teriam um alto acúmulo de calor, ou seja, $0,75^{\circ} \mathrm{C}$.

\section{Permeabilidade aos ventos}

Os ventos desempenham papel fundamental sobre os climas, pois eles contribuem para a dispersão das partículas presentes na atmosfera e para as trocas térmicas por convecção. Em se tratando de clima tropical litorâneo quente e úmido, o vento é um dos principais fatores para a redução dos altos valores de temperatura e de umidade, levando ao conforto ambiental dos usuários, em escala tanto arquitetônica, quanto urbana. Dessa maneira, a ventilação deve ser mais bem considerada nos processos de planejamento urbano.

Em se tratando do ordenamento da cidade, as dimensões e o formato dos espaços públicos - ruas, avenidas, praças e parques -, bem como a sua distribuição equilibrada no 
meio urbano, influenciam a permeabilidade aos ventos dominantes, no que se refere à direção e à velocidade. Aliando-se a geometria das vias às características das edificações e da vegetação arbórea existente, pode-se favorecer ou não a possibilidade de ventilação. A forma, a altura, a largura e a distância entre as edificações determinam a velocidade do ar que flui entre a massa edificada. Dependendo da disposição e da forma dos volumes edificados, estes podem constituir barreiras, provocar turbulências, canalizações, como também, formar diversos outros efeitos aerodinâmicos. As características de aquecimento e de emissão de calor para o ambiente são agravadas quando a forma urbana não favorece a dissipação do calor. Da cidade como um todo para o centro desta, a forma em cânion também agrava a estocagem de calor, inclusive, chegando à formação de ilhas de calor, considerando-se fatores diversos a depender de estudos específicos que identifiquem esse fenômeno em locais e em horários determinados.

Espaços completamente livres de barreiras, expostos aos ventos, como orla oceânica, topos de morros e espaços sem edificações nas proximidades podem apresentar acúmulo de calor negativo, de até $-0,25^{\circ} \mathrm{C}$. Recintos urbanos permeáveis aos ventos, como orla fluvial, encostas de morros a barlavento e espaços livres com edificações com grandes afastamentos entre si apresentam fluidez dos ventos e apresentariam acúmulo de calor nulo ou bem próximo a $0^{\circ} \mathrm{C}$. Espaços livres urbanos ladeados por edificações, porém com afastamentos que permitem os fluxos de ventos, com agrupamentos medianos de vegetação arbórea e com copas altas e/ou ralas, estão associados a baixo acúmulo de calor, em torno de $0,25^{\circ} \mathrm{C}$.
Recintos urbanos com volumes edificados com poucos afastamentos e indivíduos arbóreos com densas copas, dificultando a permeabilidade aos ventos, poderiam ocasionar um médio acúmulo de calor, próximo a $0,5^{\circ} \mathrm{C}$. Recintos urbanos com volumes edificados unitários ou em conjunto, constituindo barreiras, com agrupamentos lineares de vegetação arbórea, em ambos os lados da via, com copas densas formando túneis, dificultando tanto a exposição aos fluxos dos ventos, como a dissipação do ar quente, apresentariam alto acúmulo de calor, próximo a $0,75^{\circ} \mathrm{C}$.

\section{Permeabilidade do solo}

A superfície do solo sofre profundas alterações com o processo de urbanização, baseado, sobretudo, na substituição de superfícies naturais, permeáveis e vegetadas, por volumes edificados, estando a sua volta estacionamentos, vias e espaços mineralizados, portanto, impermeáveis.

A impermeabilização do solo modifica também a drenagem natural, levando à formação de outra distribuição das águas, tanto na horizontal, entre bacias hidrográficas, quanto na vertical, redistribuindo a destinação das águas pluviais, diminuindo a evaporação e as infiltrações, sejam elas superficiais ou profundas, e aumentando o escoamento superficial. A água que cai da chuva rapidamente vai escorrer sobre as superfícies de ruas, avenidas, pátios, até mesmo sobre canais pavimentados, enquanto mais lentamente escorreria sobre solos expostos ou vegetados. 0 aumento desse escoamento faz com que mais rapidamente o ambiente volte a ficar seco, levando à diminuição da umidade, à diminuição da evaporação e à elevação da temperatura. 
"Na cidade, a evaporação é muito reduzida. A maior parte da energia, não gasta pela evaporação, serve para aquecer as baixas camadas atmosféricas e então elevar a temperatura do ar", afirma Boussoualim (2002, p. 35). As superfícies pavimentadas apresentam elevadas temperaturas, provocando também a elevação da temperatura do ar.

O solo é considerado permeável quando permite a infiltração da água e a alimentação do lençol freático. Dessa maneira, ele conserva-se úmido por maior tempo e contribui para a diminuição da temperatura superficial do material de revestimento e da temperatura do ar. Quando o solo permeável é coberto por vegetação, o papel conservador da temperatura naturalmente amena é exacerbado, tendo em vista o metabolismo de o elemento vegetal utilizar parte da radiação solar como energia, minimizando sua emissão para o ambiente.

Dessa maneira, pode-se considerar que um recinto urbano com predominância de solo natural teria acúmulo de calor próximo a zero.

Áreas pavimentadas com materiais porosos, a exemplo de pisos cerâmicos e de cobogramas, assim como aquelas que intercalam trechos permeáveis com pequenos trechos impermeáveis, poderiam ter um acúmulo de calor baixo, ou seja, de $0,25^{\circ} \mathrm{C}$.

As áreas parcialmente pavimentadas e aquelas pavimentadas com materiais impermeáveis, mas que ainda haja um intercalar com trechos permeáveis e/ou com materiais porosos, apresentariam um acúmulo de calor médio, ou seja, de $0,50{ }^{\circ} \mathrm{C}$.

As áreas completamente pavimentadas com materiais impermeáveis, sobretudo, os materiais com baixo calor específico e com alto coeficiente de emissividade, a exemplo de concreto e asfalto, teriam um alto acúmulo de calor, ou seja, $0,75^{\circ} \mathrm{C}$.

\section{Exposição ao sol}

O Sol é nossa principal fonte de energia e fator dos mais relevantes, quando se fala em acúmulo de calor. A radiação solar direta contribui para o aumento da temperatura, para o desgaste dos materiais e para o ofuscamento, podendo vir a causar problemas de saúde. Há que se ter o cuidado de relacionar os fatores estudados neste artigo entre si, em especial este, pois tanto a alta exposição ao sol quanto a ausência dela podem trazer malefícios, sob o viés climático, consequentemente, relativos à salubridade dos espaços em escalas urbana e arquitetônica.

A forma urbana, incluindo o sistema viário e os volumes edificados, têm grande influência sobre esse fator. 0 traçado das vias, de acordo com orientação, comprimento e largura, possibilita maior ou menor exposição dos recintos ao sol, tanto quanto em relação aos volumes edificados, considerando alturas e afastamentos.

Katzschner (2007, p. 9) aponta esse fator como um dos mais importantes para a formação de climas urbanos e até para a formação de ilhas de calor nas cidades. Um quociente maior da relação entre distância e altura poderá ser positivo para o aquecimento e negativo para a ventilação, em climas frios. Ao contrário, em climas quentes e úmidos, a distância entre edificações sendo maior que a sua altura proporciona a relação positiva para a ventilação e negativa para o aquecimento, o que é bem-vindo para o conforto dos usuários. 
Um modo de se considerar a exposição ao sol é a observação do fator de céu visível, que, segundo Souza et al. (2010, p. 156), é um "parâmetro adimensional também chamado de fator de configuração ou ainda fator angular", que "indica uma relação geométrica entre a Terra e o céu e representa uma estimativa da área visível de céu", a partir de um ponto qualquer, em uma rua, uma praça, etc. Todas as barreiras físicas (edificações, vegetação, abrigos, pergolados, etc.) devem ser registradas.

Recintos urbanos, com largura inferior à média das alturas das edificações ao seu redor, gerariam fator de céu visível inferior a $30^{\circ}$, que, somado a elementos sombreadores, tais como árvores e abrigos, provocariam uma muito baixa exposição ao sol e o acúmulo de calor próximo a $0^{\circ} \mathrm{C}$.

Recintos urbanos, com largura semeIhante à média das alturas das edificações ao seu redor, gerariam fator angular entre 30 e $60^{\circ}$. A depender dos elementos sombreadores, poderiam provocar baixa exposição ao sol e baixo acúmulo de calor, em torno de $0,25^{\circ} \mathrm{C}$.

No caso de recinto de larguras superiores à média das alturas das edificações, a depender de elementos sombreadores, gerando fator de céu visível entre 60 e $90^{\circ}$, ele levaria a um médio acúmulo de calor, próximo de $0,5^{\circ} \mathrm{C}$. Por fim, recintos urbanos com largura superior à média das alturas das edificações, com ausência de elementos sombreadores e fator angular acima de $90^{\circ}$, gerariam alta exposição ao sol e alto acúmulo de calor, de $0,75^{\circ} \mathrm{C}$.

\section{Densidade construída}

A densidade construída refere-se à área total das construções já existentes, dividida pela área de um dado recorte superficial.
O processo de urbanização, em geral, ocorre paralelamente ao processo de adensamento construtivo, que pode ser por justaposição, como se verifica em zonas históricas e assentamentos populares, com edificações muito próximas umas às outras; ou por superposição de área construída, como ocorre em zonas verticalizadas. Essas duas principais alternativas aumentam a densidade construída.

$\mathrm{O}$ adensamento urbano leva à configuração de cidade compacta, que tem se constituído como um dos princípios da sustentabilidade, por otimizar o uso do espaço, a partir da aproximação de moradores, empregos, serviços e equipamentos (Gauzin-Müller, 2011, p. 55). Porém, em clima tropical quente e úmido, essa iniciativa ambiental deve ser vista com ponderação, haja vista estar associada a vários outros fatores climáticos, a exemplo da necessidade de ventilação natural para a promoção de conforto ambiental e de salubridade.

0 aumento da densidade de construção, geralmente, está associado ao desmatamento e à impermeabilização do solo, o que contribui para a elevação de temperatura superficial e, em sequência, para o aumento da temperatura do ar. Quando essa densidade é conformada por edificações muito próximas, associadas a vias estreitas, produz recintos urbanos também estreitos, o que contribui para o armazenamento de calor. Quando ocorre a combinação de proximidade e verticalização, o acúmulo de calor é agravado, pois ocorre, ao mesmo tempo, o aumento da temperatura do ar e a diminuição da velocidade dos ventos, podendo, inclusive, ocorrer o fenômeno de formação de ilhas de calor. Freitas (2008, p. 119) apresenta reflexões e cálculos, referindo-se a unidades de construção, número de habitantes em determinada 
região e sua área em hectares, classificando e relacionando densidade demográfica à densidade construída, na qual foram baseadas as classes seguintes.

Em áreas semelhantes ao entorno da estação meteorológica até a situação em que as edificações são pequenas e isoladas, com área construída muito menor que área total de referência, pode-se dizer que o acúmulo de calor seria nulo.

Em uma área urbana, já consolidada, com densidade demográfica de até 72 hab/ha e configuração apresentando edificações de um pavimento, afastamentos e alguns lotes ainda vazios, o acúmulo de calor seria baixo, em torno de $0,25^{\circ} \mathrm{C}$.

Em áreas em processo de adensamento, com a maioria dos lotes ocupados e se iniciando um processo de verticalização, alcançando-se uma densidade demográfica entre 72 hab/ha e 144 hab/ha e área construída semelhante à área total, o acúmulo de calor seria de $0,5^{\circ} \mathrm{C}$.

Áreas muito adensadas, com densidade demográfica acima de 144 hab/ha, afastamentos quase nulos, significativa verticalização e densidade construída igual ao dobro da área total de referência, teriam o acúmulo de calor estimado como alto, igual a $0,75^{\circ} \mathrm{C}$.

\section{Usos e sistema viário}

Os usos referem-se à maneira como o solo urbano é utilizado, sobretudo, quanto à destinação de suas construções e quanto às atividades que podem ser realizadas. Em um primeiro macrozoneamento, podem ser identificados o uso rural e o uso urbano. 0 uso rural apresenta uma alta quantidade de solo permeável e baixa densidade de construções, baixo fluxo de pessoas e de veículos, gerando menos calor, em relação ao uso urbano. Nas cidades, predominam os usos residenciais, comerciais e industriais, todos eles gerando fluxo de pessoas, bens e serviços, cujas atividades de produção e circulação afetam o clima, principalmente, a partir do aquecimento do ambiente. $O$ consumo de energia intensificado nas edificações, por exemplo, pelo sistema de iluminação e de climatização, os sistemas de transportes, que consomem energia proveniente, sobretudo, dos derivados do petróleo, as atividades industriais, os setores de comércio e de serviços, os resíduos das atividades humanas, tudo isso contribui para a formação e a consolidação dos climas urbanos.

A hierarquia do sistema viário é caracterizada pela dimensão das vias (comprimento e largura), pelo número de faixas, pela intensidade de fluxos, estando também diretamente relacionada à densidade de vegetação, à permeabilidade do solo, bem como aos usos e atividades. O Plano Diretor do Recife - lei n. 17.511/2008 -, por exemplo, classifica as vias em local, coletora e arterial.

As vias locais encontram-se, predominantemente, em zonas residenciais, sobretudo unifamiliares, com baixo fluxo de pessoas e de veículos. Geralmente, são em terra batida, paralelepípedo ou em intertravado, com forte presença de vegetação. Assim, associa-se à conservação da temperatura regional, ou seja, teriam acúmulo de calor próximo de zero.

Vias coletoras apresentam, em geral, uso misto, com residências, comércio e serviços, elevando o fluxo de pessoas e de veículos, piso impermeabilizado, porém ainda apresentam alguma arborização. Elas costumam ser as vias principais de um bairro e alcançariam um acúmulo de calor baixo, ou seja, de $0,25^{\circ} \mathrm{C}$. 
Vias arteriais secundárias apresentam alto fluxo de pessoas e de veículos, em área, predominantemente, comercial. Elas combinam alta densidade de construção com baixa densidade de vegetação. Geralmente, elas constituem a ligação entre bairros da cidade. Por tais características, apresentariam médio acúmulo de calor, em torno de $0,5^{\circ} \mathrm{C}$. Vias arteriais principais abrigam o uso predominantemente comercial e de serviços, através de grandes equipamentos (hipermercados, hospitais, etc.), com alto fluxo de pessoas e, mais ainda, de veículos, sobretudo, de transporte público coletivo. Elas combinam solo impermeável (asfalto ou concreto), alta densidade de construção, com muito baixa densidade de vegetação. Geralmente, elas são as principais vias da cidade, também constituindo a ligação entre zonas e cidades, no caso de regiões metropolitanas, o que tenderia a apresentar alto acúmulo de calor, chegando a $0,75^{\circ} \mathrm{C}$.

\section{Materiais de construção}

Todos os materiais realizam trocas térmicas com o meio em função da existência de diferença de temperatura. 0 calor é transferido de materiais mais "quentes" para os materiais mais "frios", até que se estabeleça o equilíbrio térmico do sistema. 0 fenômeno de trocas térmicas pode ocorrer de diferentes maneiras, sendo a principal denominada radiação, ou seja, um determinado corpo emite energia térmica, que pode ser absorvida por outro corpo, mesmo havendo certa distância entre eles. Cada material, pela sua constituição, densidade, espessura, textura, cor, realiza trocas térmicas (Frota e Schiffer, 1988, p. 31).
Os materiais de construção aqui tratados são apenas aqueles que constituem ou revestem os muros que limitam os lotes e as fachadas das edificações em volta de um determinado recinto urbano. A depender das propriedades físicas de reflexão, transmissão, absorção e emissão, esses materiais, ao terem sido aquecidos através da radiação do sol e/ ou de outros corpos (radiação direta e indireta) e ter aumentadas as suas temperaturas, podem influenciar o desempenho térmico dos ambientes urbanos. Portanto, os materiais de construção constituem-se como fatores para a formação de microclimas urbanos.

Materiais densos e lisos, com altos coeficientes de reflexão e de emissão de calor, a exemplo de concreto, granito e pedras, em geral, e escuros, como o asfalto, que absorvem uma grande parcela de radiação e a emitem de volta ao ambiente, no processo de trocas térmicas, contribuem para o aumento da temperatura em recintos urbanos. Materiais porosos e texturizados, a exemplo de certos tipos de cerâmica, e elementos com aberturas e cavidades, como os cobogós e a vegetação, principalmente, a arbórea, contribuem para a diminuição da temperatura em recintos urbanos.

Recintos urbanos conformados por edificações baixas, com fachadas em alvenaria de tijolo ou com revestimentos cerâmicos, afastadas em relação ao limite dos lotes, contando com a presença de vegetação, combinadas com cercas vivas, grades e cobogós, pouco contribuem com o acúmulo de calor, que poderia alcançar valor próximo a $0{ }^{\circ} \mathrm{C}$.

Recintos urbanos conformados por edificações de alturas diversas, que têm fachadas, predominantemente, em alvenaria de tijolo ou com revestimentos cerâmicos, afastadas 
em relação ao limite dos lotes, contando com a presença de muros verdes ou permeáveis, pouco contribuem com o acúmulo de calor, que poderia registrar valor próximo a $0,25^{\circ} \mathrm{C}$.

Espaços livres conformados por edificações e muros compostos por diversos materiais, ora absorventes, ora refletores, podem ser caracterizados pela média emissão de radiação, podendose alcançar um médio acúmulo de calor, ou seja, de aproximadamente, $0,5^{\circ} \mathrm{C}$.

Espaços cercados por edificações, predominantemente elevadas, com altos muros refletores, constituídos por materiais densos e escuros, contribuem para a geração de um alto acúmulo de calor no recinto urbano, que seria em torno de $0,75^{\circ} \mathrm{C}$.

\section{Dinâmica da volumetria}

Os volumes edificados constituem-se em fator climático antrópico, pela impermeabilização do solo que ocupam e pela sua interferência ao redor. Em virtude das propriedades de seus materiais, provocam elevação de temperatura do ar e diminuição da umidade relativa do ar. De acordo com suas formas, em largura, comprimento, altura e posição, alteram a direção e a velocidade dos ventos, além de produzirem efeitos aerodinâmicos. Os volumes geram sombras que podem incidir sobre outras edificações. Um edifício também pode gerar sombra em si mesmo, a depender da dinâmica de sua volumetria, interferindo no aquecimento/ resfriamento das superfícies externas aos volumes e no acúmulo de calor no recinto urbano, em decorrência da propagação das possíveis múltiplas reflexões de energia térmica entre suas faces e os espaços livres ao seu redor.
Para efeito de estimativa do acúmulo de calor, a dinâmica da volumetria será considerada em função das edificações que compõem um determinado recinto urbano. Como exemplo, há as fachadas planas e aquelas não planas, com volumes que constituem reentrâncias ou saliências, podendo funcionar como varandas, sacadas da face da fachada, que se permitem ser elementos sombreadores da própria fachada.

A alternância entre sol e sombra provoca diferenças de temperatura, que, por sua vez, contribuem para a geração de fluxos de ventos e para a amenização do desconforto ambiental, característico de nosso clima tropical litorâneo quente e úmido. A dinâmica da volumetria também cria alternativas de espaços de estar, considerando o caminho aparente do sol sobre a superfície terrestre. Esses espaços podem estar, ora confortáveis, ora desconfortáveis, dependendo da sua exposição à radiação solar (Romero, 2001, p. 88).

Recintos urbanos conformados por edificações com volumetrias dinâmicas, contando com reentrâncias e saliências, com a presença de sacadas, varandas, beirais, pergolados, brises e/ou marquises, pouco contribuem com o aumento da temperatura. Estes poderiam ser registrados com muito baixo acúmulo de calor, ou seja, com valores próximos a $0^{\circ} \mathrm{C}$. Os recintos conformados por edificações e muros caracterizados pela diversidade de formas e volumes, com a presença moderada de reentrâncias e saliências, podem ser caracterizados pela baixa emissão de radiação, contribuindo para um baixo acúmulo de calor, que seria de, aproximadamente, $0,25^{\circ} \mathrm{C}$. Os recintos urbanos conformados por edificações e muros caracterizados pela diversidade de formas e volumes, com o predomínio de superfícies 
Figura 1 - Linha do Tiro, Recife-PE

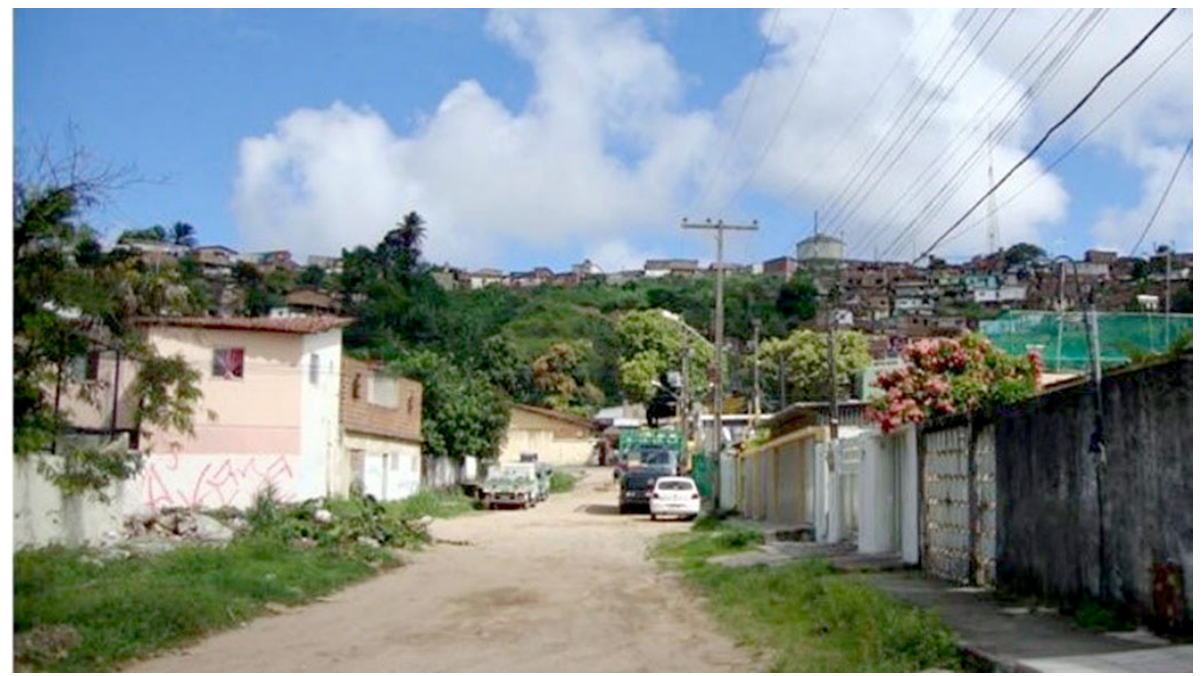

Fonte: Ruskin Freitas, em 2016.

planas, podem ser caracterizados pela média emissão de radiação, contribuindo para um médio acúmulo de calor, que poderia alcançar valor próximo a $0,5^{\circ} \mathrm{C}$. Recintos urbanos completamente cercados por edificações sem diversidade de formas e volumes, com fachadas planas e altos muros refletores, caracterizados pela alta emissão de radiação, contribuem para um alto acúmulo de calor, que ficaria em torno de $0,75^{\circ} \mathrm{C}$.

Visando-se melhor compreender a discussão, apresentam-se as figuras a seguir, em contextos completamente distintos. A Figura 1, localizada no bairro Linha do Tiro, ao norte da cidade de Recife-PE, apresenta um recinto urbano com altitude próxima a 40 metros, distante cerca de $6 \mathrm{~km}$ do oceano Atlântico, média densidade arbórea, permeável aos ventos, solo permeável, média exposição ao sol, baixa densidade construída, uso residencial em via local, materiais com médio potencial de reflexão e volumetria mediamente dinâmica. Assim, teria como resultado um baixo acúmulo de calor.

A Figura 2 apresenta um recinto urbano no bairro da Boa Vista, também em Recife-PE, com as seguintes características: área com baixa altitude, continentalidade, baixa densidade arbórea, permeável aos ventos, solo impermeável, média exposição ao sol, alta densidade construída, uso misto em uma via arterial, materiais com média refletividade, volumetria com pouco dinamismo. Tais características the confeririam um alto acúmulo de calor. 
Figura 2 - Boa Vista, Recife-PE

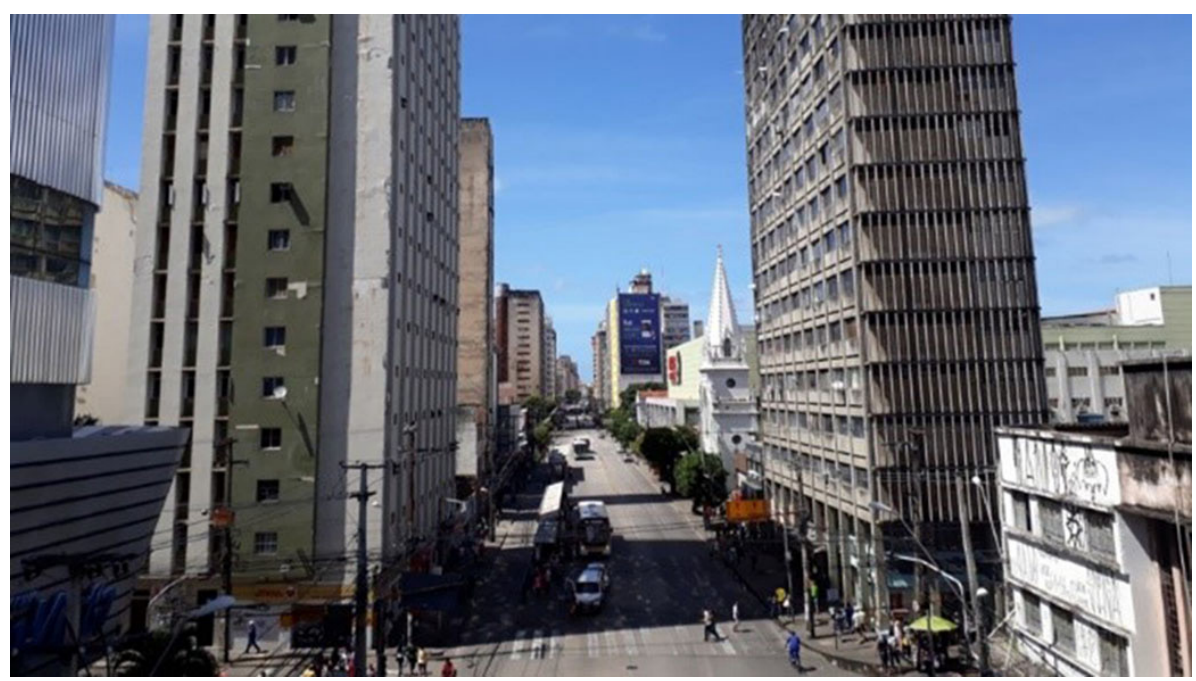

Fonte: foto de Ruskin Freitas, em 2018.

Como encaminhamento e exemplificação, apresenta-se o Quadro 3, como exercício-síntese de aplicação da metodologia, para se estimar o acúmulo de calor em recintos urbanos.

Na Figura 3, observam-se os limites do município do Recife-PE e de seus bairros. A predominância de elementos naturais leva a baixo acúmulo de calor, como em alguns recintos urbanos, localizados nos bairros Apipucos, Linha do Tiro, Curado, Cidade Universitária e na orla oceânica de Boa Viagem. A predominância de elementos construídos leva a alto acúmulo de calor, como em alguns recintos urbanos, localizados nos bairros Boa Vista e Imbiribeira. 
Quadro 3 - Exemplos de acúmulo de calor $\left({ }^{\circ} \mathrm{C}\right)$ estimado, em recintos urbanos

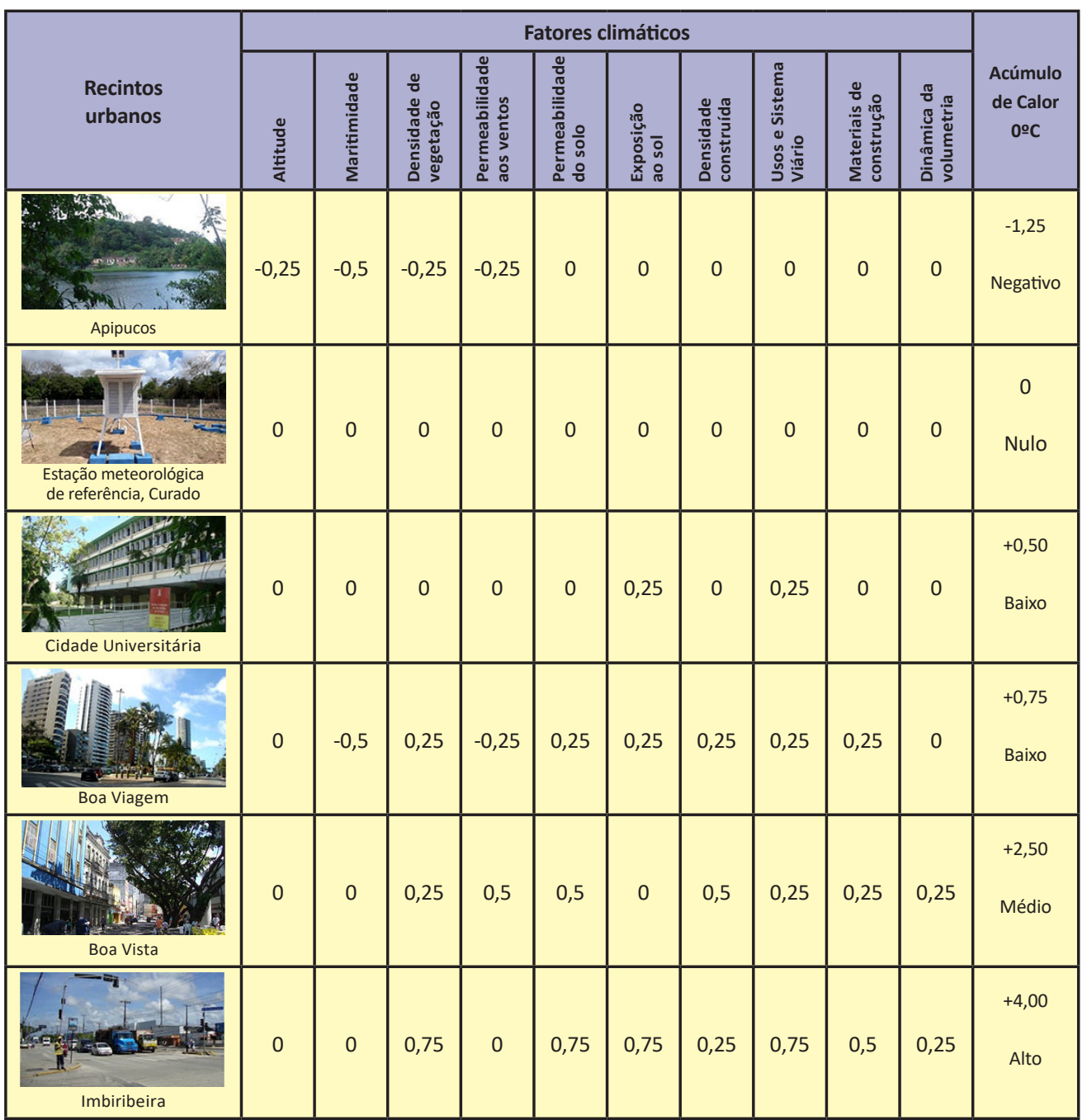

Fonte: elaboração de Ruskin Freitas. 
Figura 3 - Recife-PE, com indicação de recintos citados nas Figuras 1 e 2 e no Quadro 3

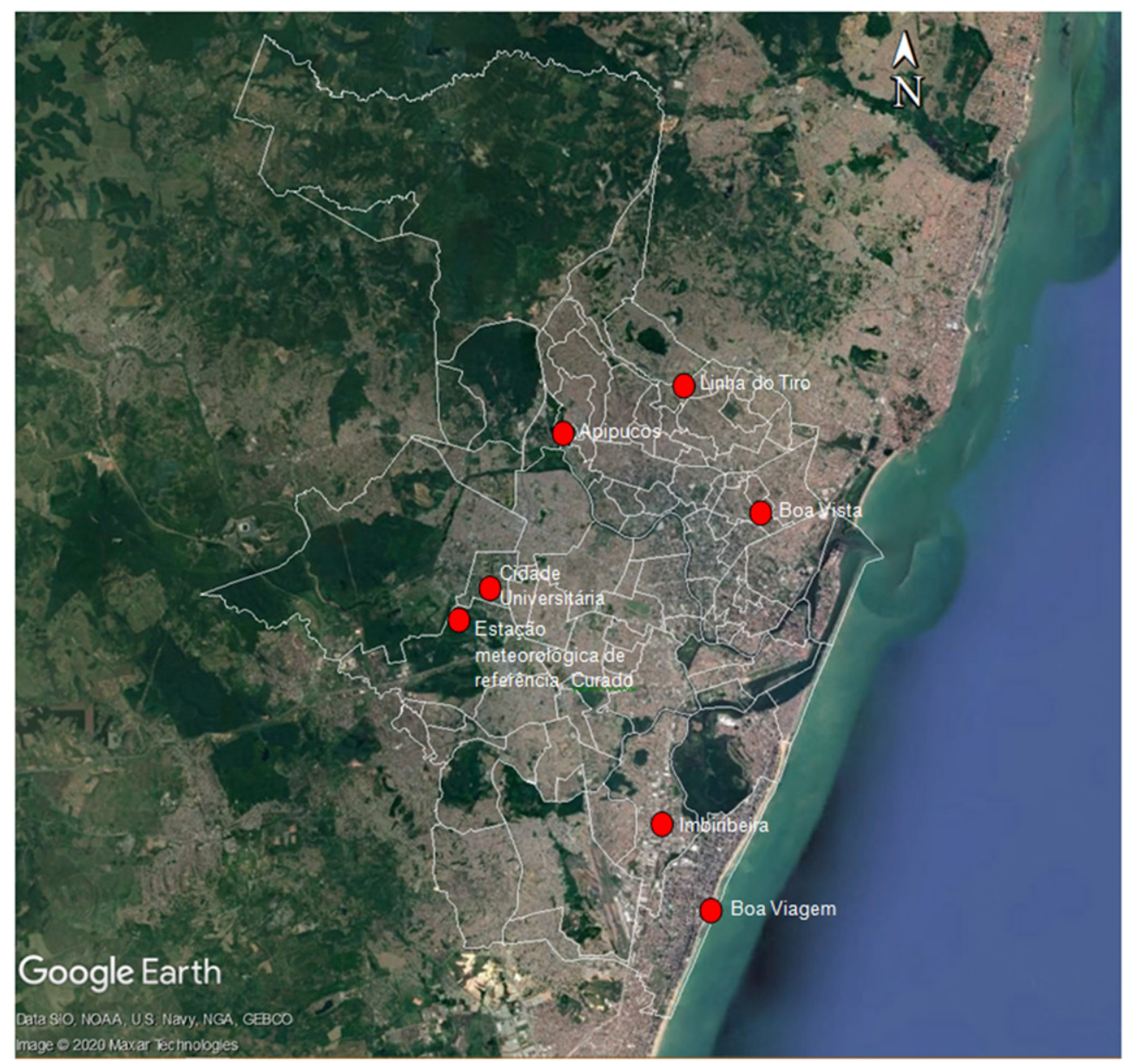

Fonte: elaboração de Jaucele Azerêdo, a partir de imagens do Google Earth e da Prefeitura do Recife. Disponível em: http://dados.recife.pe.gov.br/dataset/area-urbana/resource/e43bee60-9448-4d3d-92ff-2378bc3b5b00, acesso em 31 ago 2020 . 


\section{Considerações finais}

Tendo em vista a complexidade do sistema do clima urbano e a diversidade de variáveis envolvidas, é de fundamental importância realizar estudos relativos a cada espaço que for tomado como objeto de análise e/ou de intervenção, antes da elaboração das primeiras considerações e/ou propostas. Considerando as dificuldades operacionais para uma possível caracterização ambiental, nota-se que nem sempre é possível realizar detalhadas e sistemáticas medições de elementos climáticos em recintos urbanos.

Uma alternativa que se apresenta bastante viável para a caracterização preliminar de uma área é visitá-la e realizar mapeamento de conforto termoambiental, através de uma pesquisa de campo, usando as técnicas de observação e de percepção, ou seja, espacializar as sensações térmicas, fazendo uso de cores (por exemplo, azul, para zonas próximas ao conforto, vermelho, para zonas de desconforto, e amarelo, para zonas intermediárias), de acordo com as características físicas do recorte espacial.

Uma segunda alternativa seria, partindo-se dos valores aferidos em um ambiente natural (estação meteorológica de referência) e da observação de fatores climáticos locais, naturais e antrópicos, estimar valores térmicos em um ambiente antropizado, caracterizando uma rica diversidade urbana, tanto morfológica, quanto climático-ambiental. Para tanto, foram apresentados dez fatores climáticos locais referenciais, capazes de alterar o acúmulo de calor em um determinado recinto urbano: altitude, maritimidade, densidade de vegetação arbórea, permeabilidade aos ventos, permeabilidade do solo, exposição ao sol, densidade construída, usos e sistema viário, materiais de construção e dinâmica da volumetria.

Assim, como um recurso tático, foi desenvolvida uma metodologia para se estimar o acúmulo de calor, em função da ação conjunta desses fatores, no sentido de contribuir com o conhecimento e, em especial, com o planejamento urbano. Salienta-se que as variáveis abordadas não se encerram nos itens e valores aqui sugeridos, porém, eles podem dar uma visão clara para se comparar localidades, assim como para começar a intervir no espaço.

Os valores atribuídos ao acúmulo de calor, de maneira estimativa, em função da influência de cada fator, foram distribuídos em um escala graduada, em intervalos de $0,25^{\circ} \mathrm{C}$ e classificados em cinco níveis, de $-0,5$ a $+0,75$, correspondentes a: acúmulo de calor negativo, nulo, baixo, médio e alto acúmulo de calor.

Seguindo o mesmo raciocínio, para a classificação final de um determinado recinto urbano, deverá ser considerada a soma de valores atribuídos ao acúmulo de calor, em decorrência de cada um dos dez fatores observados. 0 valor final, entre $-1,5^{\circ} \mathrm{C}$ e $+6^{\circ} \mathrm{C}$ graus, também poderá ser classificado segundo os mesmos cinco níveis citados, negativo, nulo, baixo, médio e alto acúmulo de calor, tomando-se como referência o valor máximo da temperatura do ar encontrado na estação meteorológica de referência do Inmet, que, metodologicamente, representa o valor de uma presumida temperatura regional.

É evidente que essa metodologia não se encerra em si. É importante, em uma análise mais aprofundada, relacionar os diversos 
fatores, observando as interferências e influências recíprocas, positivas e negativas no acúmulo de calor. Portanto, esse tipo de avaliação não dispensa a pesquisa aprofundada e as medições sistemáticas de condições atmosféricas, edilícias e urbanas, como contribuição ao planejamento urbano, ao projeto de edificações e ao conforto ambiental. Porém, em caso de necessidade de uma avaliação preliminar, ela tem grande utilidade. Também é validada a importância de estudos nessa área de conhecimento como contribuição a possíveis revisões de legislação urbanística e arquitetônica, ao se comprovar o quanto cada elemento inserido em meio urbano interfere na contribuição do acúmulo de calor.

Por exemplo, se uma determinada área passa por intenso processo de urbanização, concomitantemente ao aumento da densidade de ocupação, de verticalização e de impermeabilização do solo, provavelmente, ocorrerá aumento de temperatura e perda de qualidade ambiental. Com a aplicação dessa metodologia ora apresentada, pode-se chegar à simulação de cenários, nos quais se poderia ser estimada a diferença de temperatura, através da estimativa de acúmulo de calor, nas situações anterior e posterior às mudanças a serem propostas, tais como aumento da taxa de solo natural, diminuição da taxa de ocupação e maiores afastamentos entre edificações.
O calor acumulado no espaço urbano interfere, diretamente, para a qualidade dos espaços livres, tanto quanto para o conforto ambiental dos usuários de espaços internos, considerando as interfaces entre diferentes sistemas. Se explorarmos essas mudanças climáticas locais, de maneira mais aprofundada e abrangente, também poderemos chegar a registrar as suas contribuições para as mudanças climáticas globais.

Ora, se uma cidade como Recife, com 1,7 milhão de habitantes em seu município e com mais de 4 milhões em sua Região Metropolitana, apresenta uma diferença de até $6^{\circ} \mathrm{C}$, entre suas localidades internas, pode-se, por analogia com áreas-tipo, também se calcular o acúmulo de calor em outras localidades, principalmente, de características metropolitanas, em que são exacerbadas as diferenciações ambientais, morfológicas e socioeconômicas.

A aplicação dessa metodologia, por técnicos e gestores urbanos, ou mesmo por estudantes e cidadãos comuns, poderá orientar intervenções que promovam a satisfação do usuário, a eficiência do espaço construído e a sustentabilidade ambiental. Fica a expectativa de que outros estudos sejam desenvolvidos, para consolidar as considerações feitas para o contexto de uma metrópole em clima tropical litorâneo quente e úmido, assim como para outros contextos, morfológicos e ambientais.

\section{[I] https://orcid.org/0000-0001-7347-8302}

Universidade Federal de Pernambuco, curso de Arquitetura e Urbanismo, Programa de Pós-Graduação em Desenvolvimento Urbano. Recife, PE/Brasil.

ruskin37@uol.com.br

\section{[II] https://orcid.org/0000-0002-5853-8052}

Universidade Federal de Pernambuco, curso de Arquitetura e Urbanismo, Recife, PE/Brasil. jaucele_azeredo@hotmail.com 


\section{Referências}

ALMEIDA, E. M. A. (2019). A cidade como um sistema complexo: transformações morfológicas e climáticas em Maceió. Tese de doutorado. Maceió, Universidade Federal de Alagoas.

ALVIN, A. T. B.; KATO, V. R. C.; ROSSIN, J. R. G. (2015). A urgência das águas: intervenções urbanas em áreas de mananciais. Cadernos Metrópole. São Paulo, v. 17, n. 33, pp. 83-107.

AYOADE, J. O. (1991). Introdução à climatologia para os trópicos. Rio de Janeiro, Bertrand do Brasil.

AZERÊDO, J. F. F. A. (2017). Verde que te quero confortável: a contribuição da arborização urbana para o conforto termoambiental ao nível do usuário pedestre. Tese de doutorado. Recife, Universidade Federal de Pernambuco.

BARROS, H. R.; LOMBARDO, M. A. (2013). Zoneamento climático urbano da cidade do Recife: uma contribuição ao planejamento urbano. GEOUSP - espaço e tempo. São Paulo, n. 33, pp. 187-197.

BOUSSOUALIM, A. (2002). Contribuition à la caracterérisations de l'impact et de l'incidence du microclimat sur l'usage et les activités em espace public exterior-étude de cas à Blangnac. Thèse de doctorat. Nantes, École Polytechnique.

CARVALHO, L. T. (2018). Mapas climáticos: instrumentos para o planejamento urbano. Trabalho de Conclusão de Curso. Recife, Universidade Federal de Pernambuco.

FERRARO, N. G.; SOARES, P. A. T. (1998). Física básica. São Paulo, Atual.

FREITAS, R. (2008). Entre mitos e limites: as possibilidades do adensamento construtivo face à qualidade de vida no ambiente urbano. Recife, Editora Universitária da UFPE.

FREITAS, R.; AZERÊDO, J. (2014). A disciplina conforto ambiental: uma ferramenta prática na concepção de projetos de arquitetura, de urbanismo e de paisagismo. Cadernos Proarq. Rio de Janeiro, n. 20, pp. 94-113.

FRANÇA, L. et al. (2015). “Análise do desconforto térmico causado pela ilha de calor urbana em um bairro do Recife-PE utilizando sensoriamento remoto". In: XVII SIMPÓSIO BRASILEIRO DE SENSORIAMENTO REMOTO. Anais... João Pessoa, INPE.

FROTA, A.; SCHIFFER, S. (1988). Manual de conforto térmico. São Paulo, Nobel.

GAUZIN-MÜLLER, D. (2011). Arquitetura ecológica. São Paulo, Senac.

INSTITUTO NACIONAL DE METEOROLOGIA. Normais climatológicas do Brasil 1981-2010. Disponível em: <http://www.inmet.gov.br/portal/index.php?r=clima/normaisClimatologicas>. Acesso em: 22 abr 2020.

HALLIDAY, D.; RESNICK, R; WALKER, J. (2012). Fundamentos de física: gravitação, ondas e termodinâmica. Rio de Janeiro, LTC.

KATZSCHNER, L. (2007). New developments in applied urban climatology. In: IX ENCONTRO NACIONAL E V ENCONTRO LATINO-AMERICANO DE CONFORTO NO AMBIENTE CONSTRUÍDO. Anais... Ouro Preto, Entac.

LANDSBERG, H. (1981). The urban climate. Nova York, Academic Press.

LOMBARDO, M. (1985). Ilha de calor nas metrópoles. São Paulo, Hucitec.

MASCARÓ, L.; MASCARÓ J. (2002). Vegetação urbana. Porto Alegre, Masquatro. 
MASCARÓ, L. (coord.). (1996). Estudo da influência do adensamento da cidade de Porto Alegre na ventilação urbana. Porto Alegre, UFRGS.

MENDONÇA, F.; DANNI-OLIVEIRA, I. M. (2009). Climatologia: noções básicas de climas no Brasil. São Paulo, Oficina de Textos.

MONTEIRO, C. A. F.; MENDONÇA, F. (2003). Clima urbano. São Paulo, Contexto.

MONTEIRO, C. A. F. (1976). Teoria e clima urbano. Tese de livre-docência. São Paulo, Universidade de São Paulo.

MOREIRA, E. et al. (2017). O modelo sebal para estudos de clima intraurbano: aplicação em Recife, Pernambuco, Brasil. Revista Raega. Curitiba, v. 39, pp. 247-265.

OKE, T. et al. (2017). Urban Climates. Cambridge, Cambridge University Press.

PIRES, A. C. F.; KNEIB, E. C.; RIBEIRO, R. J. C. (2020). Impactos da metropolização no sistema de transporte coletivo: estudo de caso na Região Metropolitana de Goiânia. Cadernos Metrópole. São Paulo, v. 22, n. 47, pp. 247-272.

PREFEITURA MUNICIPAL DE RECIFE (2008). Lei n. 17.511/2008 - O Plano Diretor do Recife.

RIBEIRO, C. A. M.; BRAZ, A.; SILVA, F. (2013). Mapa de análises climáticas de João Pessoa - Paraíba. In: XII ENCONTRO NACIONAL E VIII ENCONTRO LATINO-AMERICANO DE CONFORTO NO AMBIENTE CONSTRUÍDO. Anais... Brasília, Antac.

ROMERO, M. (2001). Arquitetura bioclimática do espaço público. Brasília, UnB.

SCHUTZER, J. G. (2012). Cidade e meio ambiente: a apropriação do relevo no desenho ambiental urbano. São Paulo, Editora da Universidade de São Paulo.

SOUZA, L. C. L. et al. (2010). Fator de visão do céu e intensidade de ilhas de calor na escala do pedestre - Sky view factor and urban heat islands intensity at the pedestrian level. Ambiente Construído. Porto Alegre, v. 10, n. 4, pp. 155-167.

STEWART, I. D.; OKE, T. R. (2012). Local climate zones for urban temperature studies. Disponível em: <http://journals.ametsoc.org/bams/article-pdf/93/12/1879/3739321/bams-d-11-00019_1. pdf $>$. Acesso em: 27 ago 2020.

TARIFA, J. R.; AZEVEDO, T. R. (2001). Os climas da cidade de São Paulo: teoria e prática. São Paulo, Geousp.

UNITED NATIONS, DEPARTMENT OF ECONOMIC AND SOCIAL AFFAIRS, POPULATION DIVISION (2017). World Population Prospects: the 2017 Revision, Key Findings and Advance Tables. Working Paper n. ESA/P/WP/248. Nova York, United Nations.

UNITED NATIONS, DEPARTMENT OF ECONOMIC AND SOCIAL AFFAIRS, POPULATION DIVISION (2019). World Urbanization Prospects: the 2018 Revision (ST/ESA/SER.A/420). Nova York, United Nations.

Texto recebido em $4 /$ maio/2020

Texto aprovado em 8/out/2020 